\title{
Non communicable disease and risky behaviour in an urban university community Nigeria
}

\author{
*Ige OK, Owoaje ET, Adebiyi OA
}

Department of Community Medicine, University College Hospital, Ibadan, Nigeria

\begin{abstract}
Background: Most developing countries have only limited information on the burden of Non Communicable Diseases (NCDs) even though rapid transitions in these NCDs have been predicted.

Objectives: To describe the burden of selected NCDs and associated risk behaviours in an urban university community in Nigeria.

Methods: A cross-sectional survey of 525 representative staff of a University in a large city in Nigeria was conducted.

Results: In all, 27.6\% were already diagnosed with at least one NCD (hypertension- $21.5 \%$, diabetes-11\%, cancer 2.9\%) while $67.4 \%$ reported at least one risk behaviour (unhealthy diet- $96 \%$, sedentary living- $27.4 \%$ excessive alcohol use-5.1\% and smoking-1.9\%). Multiple risk behaviours were observed in $29.9 \%$ with no significant variation by sex or age. Those 40 years and above had significantly higher prevalence of NCD, particularly for hypertension ( $\mathrm{p}<0.05)$. Only $7 \%$, considered themselves to be at risk of NCDs. Those whose parents had NCDs OR: 5.9 (2.4-14.5) and those who currently had NCDs OR: 3.9(1.8-8.1) perceived themselves at risk of one or more NCDs, but not those with multiple risk behaviours.

Conclusion: The high burden of NCDs and risk behaviours in the face of limited self-perceived risk has been demonstrated and calls for urgent intervention.

Keywords: Non communicable disease, risk behaviour, Nigeria

African Health Sciences 2013; 13(1): 62 - 67 http://dx.doi.org/10.4314/ahs.v13i1.9
\end{abstract}

\section{Introduction}

The twentieth century heralded one of the most accelerated health transitions which has brought noncommunicable diseases (NCDs) to the forefront of global public health challenges. NCDs now account for most of the global burden of disease and an increasing burden has been forecasted in the decades ahead, particularly in low and middle income countries. ${ }^{1}$ This epidemiologic transition has been linked to urbanization, industrialization and globalization leading to lifestyle changes that promote NCDs. ${ }^{2}$ The influences of urbanization are also apparent in the most Nigerian cities, with the increasing use of motorized transport and sedentary types of occupation such as trade and office work. This is also usually accompanied by other high risk dietary and lifestyle behaviours., ${ }^{3,5}$. Cardiovascular disease, diabetes and cancers which account for a major share of the burden of NCDs also share common lifestyle related risk factors. These risk factors include poor dietary habits (excessive calorie

\section{*Corresponding author:}

Dr Olusimbo Kehinde Ige

Department of Community Medicine

University College Hospital

Ibadan, Nigeria

Tel: +2348054460286

E-mail: drsimbo@yahoo.co.uk and inadequate fruit and vegetable intake), excessive alcohol use, physical inactivity and tobacco use. ${ }^{6}$ The emerging evidence of the increasing burden of NCD and the risk factors in Sub Saharan Africa should have provoked targeted public health intervention. However, in Nigeria the lack of data on health and economic burdens attributable to NCDs particularly in urban areas have prevented the actions needed to curb this rising toll of NCDs. This study aims to place additional evidence in the public domain by documenting the self-reported prevalence of selected NCDs and associated risk behaviours among university workers as a high risk population in urban southern Nigeria.

\section{Methods}

The study was carried out in a University community located in the city of Ibadan, Oyo State, South Western Nigeria. The institution is located in an urban area and the staff are from an admixture of different ethnic groups with the Yoruba constituting the majority. The staff strength of the University is 4,500. The senior staff are 3,100 and are made up of academic staff, senior secretarial staff, senior nonsecretarial staff and senior technical staff. The junior staff consists of 1,400 workers who are either junior technical or non-technical staff. A cross sectional 
survey of 547 members of staff (academic and nonacademic) of the University was conducted. Respondents were selected using a two stage sampling technique. The first stage involved the simple random sampling of departments; four departments were selected from each of the 15 faculties in the University by balloting from a list of all the departments in each faculty. The second stage involved systematic sampling of listed staff members from each selected department, 10 staff members were thus selected from each of the 60 departments selected in stage one. Data were collected using structured self administered questionnaires. The questionnaire was adapted from The Behavioural Risk Factor Surveillance System questionnaire. ${ }^{8}$ Three of the major NCDs which contribute to increased mortality in adult Nigerians, Hypertension, Diabetes and Cancer $^{4}$ were assessed.

Approval for the study was obtained from the University of Ibadan Institutional review board. Written informed consent was also obtained from respondents before administering questionnaires.

\section{Outcome measures}

Disease burden: Self- reported prevalence of specified NCDs was assessed by asking if a doctor had ever diagnosed respondents with any of the listed NCDs. Prevalence of NCD associated risk behaviours: smoking, alcohol excess, unhealthy diet and sedentary living were also assessed by self-report. The measures of risk behaviours are as specified by the Centre for Chronic Disease Prevention and Health':

Unhealthy diet: was defined as lack of daily intake of fruits and/or vegetables (cooked or uncooked) and/or daily intake of high fat or high sugar meals ( i.e consumption of soft drinks, fried food, pastries and other confectioneries one or more times daily). ${ }^{9-}$ 10

Inadequate physical inactivity (sedentary living): Lack of regular, sustained activity i.e. when the total physical activity was below the recommended (i.e. $<30$ minutes of moderate activity per day for at least 3 days/week). Respondents who reported no physical activity in form of a formal exercise regimen and whose job was mostly done sitting or standing were classified as having inadequate physical activity inactive/sedentary. Physical activity was derived by computing the following three criteria:

Levels of exercise intensity (e.g walking, gardening e.t.c $=$ moderate, while jogging, swimming etc $=$ vigorous $)]+$ frequency of exercising per week (days/week) + Daily duration of each performed activity in minutes.

Excessive alcohol intake: Female respondents who reported an average daily alcohol consumption of $>1$ drink. Male respondents who reported an average daily alcohol consumption of $>2$ drinks. One drink is defined as one shot of spirits (such as Bourbon, Scotch, Vodka, Gin, etc.), one glass of wine or half a bottle of beer.

Current smoking: Smoking cigarettes every day or some days in the last 30 days.

Multiple risk behaviour: was defined as having two or more risk behaviours.

\section{Data management}

Analysis was done with SPSS version 16 software. The Chi Square test and Binary logistic regression analysis were used to explore associations at a 5\% significance level.

\section{Results}

The response rate was $95.9 \%$ (525 out of 547 ), some questionnaires could not be retrieved because the respondents were unavailable after three visits.

The socio-demographic characteristics of respondents are shown in table I. The mean age was $37.4 \pm 9.5,51.2 \%$ were males and $96.6 \%$ had at least secondary education. The majority $(82.5 \%)$ were Yoruba.

The job characteristics of respondents are shown in table 2. Academic staff constituted about a third $(33.5 \%)$ of respondents, other non academic staff made up the rest of the sample with the support staff having the largest percentage $(18.5 \%)$. The proportion of senior cadre staff slightly exceeded that of the junior cadre $(52.4 \%$ versus $47.6 \%)$. The majority $(76.6 \%)$ spent the bulk of their work hours sitting or standing. 
Table 1: Socio-Demographic characteristics of respondents

\begin{tabular}{ll}
\hline Variable & $\mathbf{N}=\mathbf{5 2 5}(\mathbf{\%})$ \\
\hline Age & \\
$<40$ & $326(62.1)$ \\
40 and above & $199(37.9)$ \\
Sex & \\
Male & $269(51.2)$ \\
Female & $256(48.8)$ \\
Marital Status & \\
Married & $378(72.0)$ \\
Never married & $130(24.8)$ \\
Others* & $17(3.2)$ \\
Educational level & \\
Primary & $18(3.4)$ \\
Secondary & $61(11.6)$ \\
Tertiary & $263(50.1)$ \\
Postgraduate & $183(34.9)$ \\
Religion & \\
Christianity & $457(87.0)$ \\
Islam & $68(13.0)$ \\
Tribe & \\
Yoruba & $433(82.5)$ \\
Other tribes & $92(17.5)$ \\
*Divorced, separated or widowed & \\
&
\end{tabular}

Table 2: Job characteristics of respondents

\begin{tabular}{ll}
\hline Job characteristics & $\mathbf{N}=\mathbf{5 2 5}(\mathbf{\%})$ \\
\hline Job description & $\mathbf{1 7 6 ( 3 3 . 5 )}$ \\
Academic & $37(7.0)$ \\
Secretarial & $66(12.6)$ \\
Technical & $87(16.6)$ \\
Administrative & $62(11.8)$ \\
Clerical staff & $97(18.5)$ \\
Support staff & \\
Staff category & $250(47.6)$ \\
Junior staff & $275(52.4)$ \\
Senior staff & \\
Nature of work & \\
Mostly sitting/standing & $402(76.6)$ \\
Mostly walking & $85(16.2)$ \\
Mostly heavy labour/ & $38(7.2)$ \\
physically demanding work
\end{tabular}

Table 3: Reported risk behaviours by sex and age group

\begin{tabular}{|c|c|c|c|c|c|}
\hline \multirow[b]{2}{*}{ Risk behaviour } & \multicolumn{4}{|c|}{ Sex } & \multirow[b]{2}{*}{$\mathbf{P}$ value } \\
\hline & Male n (\%) & Female n $(\%)$ & \multicolumn{2}{|c|}{ Total n $(\%)$} & \\
\hline Inadequate physical activity & $68(25.3)$ & $76(29.7)$ & \multicolumn{2}{|c|}{$144(27.4)$} & 0.251 \\
\hline Excessive alcohol intake & $21(7.8)$ & $6(2.3)$ & \multicolumn{2}{|c|}{$27(5.1)$} & 0.005 \\
\hline Unhealthy diet & $255(94.8)$ & $249(97.3)$ & \multicolumn{2}{|c|}{$504(96.0)$} & 0.149 \\
\hline Tobacco smoking & $9(3.3)$ & $1(0.4)$ & \multicolumn{2}{|c|}{$10(1.9)$} & 0.013 \\
\hline \multirow[t]{2}{*}{ Multiple risk behaviours } & $78(29.1)$ & $79(30.9)$ & & $7(29.9)$ & 0.641 \\
\hline & \multicolumn{4}{|c|}{ Age group } & \\
\hline Risk behaviour & $<40$ years $\mathrm{n}(\%)$ & $>40$ years & $(\%)$ & Total n (\%) & $\mathbf{P}$ value \\
\hline Inadequate physical activity & $93(28.5)$ & $51(25.6)$ & & $144(27.4)$ & 0.476 \\
\hline Excessive alcohol intake & $16(4.9)$ & $11(5.5)$ & & $27(5.1)$ & 0.755 \\
\hline Unhealthy diet & $316(96.9)$ & $188(94.5)$ & & $504(96.0)$ & 0.163 \\
\hline Tobacco smoking & $4(1.2)$ & $6(3.0)$ & & $10(1.9)$ & 0.146 \\
\hline Multiple risk behaviours & $103(31.6)$ & $54(27.1)$ & & $157(29.9)$ & 0.279 \\
\hline
\end{tabular}

Table 4: Reported non- communicable diseases by sex and age-group

\begin{tabular}{|c|c|c|c|c|}
\hline \multicolumn{5}{|c|}{ Sex } \\
\hline History of NCD & Male n $(\%)$ & Female n (\%) & Total n (\%) & $\mathrm{p}$ value \\
\hline Diagnosed with any NCD & $57(21.2)$ & $68(26.6)$ & $125(23.8)$ & 0.149 \\
\hline Type 2 Diabetes & $31(11.6)$ & $27(10.5)$ & $58(11.1)$ & 0.710 \\
\hline Hypertension & $59(21.9)$ & $54(21.1)$ & $113(21.5)$ & 0.815 \\
\hline \multirow[t]{2}{*}{ Cancer } & $10(3.7)$ & $5(2.0)$ & $15(2.9)$ & 0.225 \\
\hline & \multicolumn{3}{|c|}{ Age group } & \\
\hline History of NCD & $<40$ years $n(\%)$ & \multicolumn{2}{|c|}{$>40$ years $n(\%)$ Total $n(\%)$} & $\mathrm{p}$ value \\
\hline Diagnosed with any NCD & $55(16.9)$ & $70(35.2)$ & $125(23.8)$ & $<0.001$ \\
\hline Type 2 Diabetes 3 & $7(11.4)$ & $21(10.6)$ & $58(11.1)$ & 0.768 \\
\hline Hypertension & $61(18.7)$ & $52(26.1)$ & $113(21.5)$ & 0.045 \\
\hline Cancer & $9(2.8)$ & $6(3.0)$ & $15(2.9)$ & 0.865 \\
\hline
\end{tabular}


Table 5: Factors associated with self perceived risk of NCD

\begin{tabular}{llcc}
\hline $\begin{array}{l}\text { Variables } \\
\text { Sex }\end{array}$ & OR & $\begin{array}{c}\text { 95\% Confidence } \\
\text { interval }\end{array}$ & P value \\
\cline { 2 - 4 } $\begin{array}{l}\text { Fale } \\
\text { Staff Category }\end{array}$ & 0.77 & $0.37-1.60$ & 0.487 \\
$\begin{array}{l}\text { Junior staff } \\
\text { Senior staff }\end{array}$ & 1 & & \\
$\begin{array}{l}\text { Age } \\
<40 \text { years }\end{array}$ & 0.68 & $0.31-1.50$ & 0.336 \\
$>\quad 10$ years & 1.05 & $0.47-2.35$ & 0.902 \\
$\begin{array}{l}\text { Marital status } \\
\text { Married }\end{array}$ & 1 & & \\
$\begin{array}{l}\text { Not married } \\
\text { Family history of NCD }\end{array}$ & 1.93 & $0.61-6.16$ & 0.267 \\
$\begin{array}{l}\text { Yes } \\
\text { No }\end{array}$ & 5.89 & $2.39-14.47$ & 0.000 \\
$\begin{array}{l}\text { Personal history of NCD } \\
\text { Yes }\end{array}$ & 1 & & \\
No & 3.85 & $1.83-8.08$ & 0.000 \\
$\begin{array}{l}\text { Multiple risk behaviour } \\
\text { Yes }\end{array}$ & 1 & & \\
No & 2.00 & $0.96-4.17$ & 0.064 \\
\hline
\end{tabular}

\section{Risk behaviours for NCDs}

Of all risk behaviours reported, unhealthy diet was the most predominant 504(96\%) while smoking featured the least 10(1.9\%). Males had higher proportions who consumed excessive alcohol and who smoked compared to females ( $p>0.05)$. None of the reported risk behaviours differed significantly by age ( $p>0.05)$, in table 3. Multiple risk behaviours were observed in $29.9 \%$ with no significant variation by sex or age. Most respondents reported one risk behaviour (67.4\%), only $0.2 \%$ reported all four risk behaviours.

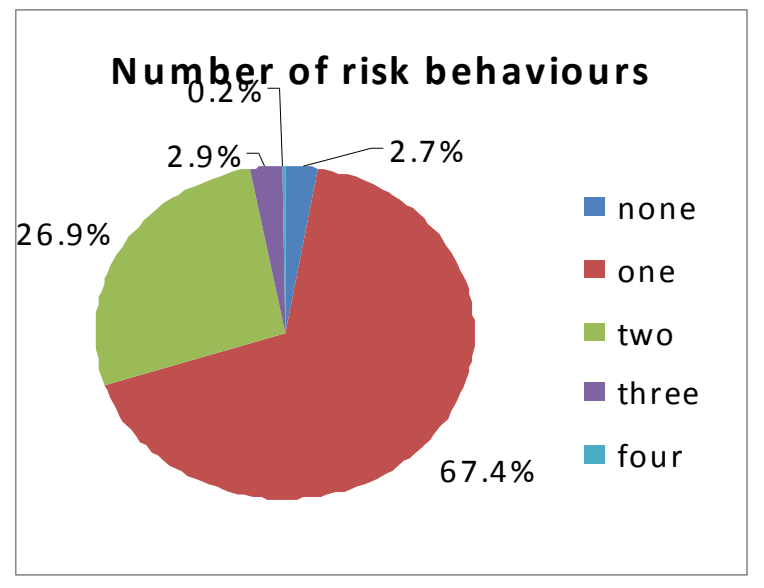

Figure 1: Number of reported risk behaviours

\section{NCD burden}

Over a quarter 27.2\% [23.48\%-31.26\%] had been diagnosed to have at least one of the specified NCDs. The most prevalent NCD was hypertension $(21.5 \%)$ and the least cancer $(2.9 \%)$. The prevalence of NCDs did not vary significantly by sex ( $\mathrm{p}>0.05)$. However those age 40 years and above had significantly higher prevalence of any NCD, particularly for hypertension $(p<0.05)$ See Table IV

\section{Self perceived risk of NCD}

Only 37(7\%), of respondents considered themselves to be at risk of developing new/additional NCD. The determinants of this self perceived risk are shown in table 4. Those whose parents had NCDs OR: 5.9 (2.4-14.5) and those who already had NCD OR: $3.9(1.8-8.1)$ were more likely to perceive themselves at risk of a new/additional NCDs. Those with multiple risk behaviours did not differ significantly from those without in their self perceived risk.

\section{Discussion}

This study describes the prevalence of selected NCDs and associated risk behaviours in a university community in south west Nigeria. Even though estimates of NCDs was by self-report, the reported 
prevalence of hypertension and diabetes compared with other local data. ${ }^{11-12}$ The current burden of diabetes however exceeds the estimated prevalence rate of $2.8 \%$ for type 2 diabetes for Africa. ${ }^{13}$ The reported prevalence of cancer in this study also exceeds previous estimates. ${ }^{14}$ Increasing age emerged as a significant risk factor for NCDs which underscores the importance of lifestyle modification with increasing age.

The future seems even more ominous with almost 7 in ten reporting at least one risk behaviour and about 3 in 10 having multiple risk behaviours. This study agrees with previous findings from both developing and developed countries which have demonstrated clustering of risk behaviours in selected urban populations. ${ }^{915-17}$ This clustering of risk behaviours have been associated with higher overall risks of NCDs than individual risk behaviours and such diseases as hypertension, cancer and diabetes have been linked to multiple risk behaviours. ${ }^{18}$ The overwhelming prevalence of unhealthy diet reiterates findings from review of behavioural risk factors in developing countries in which just 5\% were documented to consume at least five combined servings of fruit and vegetables per day. ${ }^{19}$ This might partly explain the observed increase in NCDs and indicates the need for targeted intervention.

Although those with a family history and personal history of NCDs more often considered themselves at risk of NCD, this was not so for those with multiple risk behaviours. This confirms that generally there is a tendency for people to underestimate their own health risks compared to those of others. This unrealistic optimism about personal risk and susceptibility to disease probably also affects the individual's decision making in favour of taking greater risks than he rationally should and places him at greater risk of disease. ${ }^{20}$

This study has illuminated the burden of NCDs and associated risk behaviours in urban Nigeria. This also portends a sharp rise in the future burden of NCDs with the magnitude of multiple risk behaviours. If the present trend continues, the health system will be unable to support the impending rise in the burden of disease. The size of the current and expected future burden based observed risk behaviours and the apparent lack of self perceived risk in those with multiple risk behaviours demands urgent public health interventions. Intervention strategies for NCDs should prioritise risk behaviours and aim at recognising, preventing and reducing these risk factors for NCDs. Improved surveillance of
NCDs within Nigeria and in sub-Saharan Africa is needed in order to place non-communicable diseases properly within the context of the overall burden of disease.

\section{Study limitations}

The history of NCDs as reported by study participants may be subject to bias since many NCDs though present may be unapparent making under reporting a possibility. The prevalences presented here may thus underestimate the actual prevalence of non communicable diseases in the population, but given the similarity of results to previous other data we do not expect this to substantially limit the usefulness of the results. The study population is from a high risk urban population due to the high proportion of blue and white collar workers in the university community. Although the university workforce is drawn from a heterogeneous group of urban dwellers, these workers may be at higher risk due to the more westernised work environment with ready access to motorized transportation and fast foods compared to other urban dwellers and so caution is required in considering the generalizability of the results. A particular strength of this study however is the demonstration of the clustering of risk behaviours showing the need for multipronged prevention strategies. However, further epidemiological research is needed into the prevalence of and risk factors for NCDs in a range of settings in Nigeria.

\section{Conclusion}

The high burden of NCDs and risk behaviours in the face of limited self-perceived risk has been demonstrated and calls for urgent intervention.

\section{References}

1. WHO. The world health report 2003: shaping the future. Geneva: World Health Organization2003.

2. Aikins Ad-G, Unwin N, Agyemang C, Allotey P, Campbell C, Arhinful D. Tackling Africa's chronic disease burden: from the local to the global. Globalization and Health. 2010;6(5): doi:10.1186/1744-8603-6-5

3. Tesfaye F, Byass P, Wall S. Population based prevalence of high blood pressure among adults in Addis Ababa: uncovering a silent epidemic. BMC Cardiovascular Disorders. 2009; 9(39): doi:10.1186/1471-2261-9-39 
4. Steyn K, Damasceno A, editors. Lifestyle and Related Risk Factors for Chronic Diseases. 2nd ed ed2006.

5. Unwin N, Alberti K. Chronic noncommunicable diseases. Annals of tropical medical parasitology. 2006;100(5-6):455-64.

6. Derman E, Patel DN, Nossel C, Schwellnus M. Healthy lifestyle interventions in general practice. SA Fam Pract. 2008;50(4):6-12.

7. World Health Organization. World Health Report 2002. Reducing risks, promoting healthy life. Geneva: WHO2002.

8. CDC. Behavioural risk factor surveillance system questionnaire (2009). 2009 [cited 2009 June 2]; Available from: www.cdc.gov/brfss/.

9. CDC. Chronic Disease Indicators: National Center for Chronic Disease Prevention and Health Promotion2005.

10. Krauss RM, Deckelbaum RJ, Ernst N, Fisher E, Howard BV, Knopp RH, et al. Dietary Guidelines for Healthy American Adults: A Statement for Health Professionals From the Nutrition Committee, American Heart Association. Circulation. 1996;94(7):1795-800.

11. WHO. World health stattistics 2008. Geneva: WHO 2009.

12. Adedoyin R, Mbada C, Balogun M, Martins T, Adebayo R, Akintomide A, et al. Prevalence and pattern of hypertension in a semiurban community in Nigeria. Eur J Cardiovasc Prev Rehabil. 2008;15:683-7.

13. BeLue R, Okoror TA, Iwelunmor J, Taylor KD, Degboe AN, Agyemang C, et al. An overview of cardiovascular risk factor burden in subSaharan African countries: a socio-cultural perspective Global Health. 2009; 5(10): ????

14. WHO. Global Burden of Disease. 2002 [cited 2010 October 10]; Available from: https:// apps.who.int/infobase/Comparisons.

15. Lawder R, Harding O, Stockton D, Fischbacher C, Brewster D, Chalmers J, et al. Is the Scottish population living dangerously? Prevalence of multiple risk factors: the Scottish Health Survey 2003. BMC Public Health. 2010;10(1):330.

16. Nakanishi N, Suzuki K, Tatara K. Clustering of cardiovascular risk factors and risk of development of hypertension in Japanese male office workers. J Cardiovasc Risk. 2003;10:21320.

17. O'Loughlin J, Maximova K, Tan Y, GrayDonald K. Lifestyle Risk Factors For Chronic Disease Across Family Origin Among Adults in Multiethnic, Low-income, Urban Neighbourhoods. Ethnicity \& Disease. 2007;17:657-63.

18. WHO. Global Burden of Disease. 2002 [cited 2010 October 10]; Available from: https:// apps.who.int/infobase/Comparisons.

19. Khatib O. Noncommunicable diseases: risk factors and regional strategies for prevention and care. East Mediterr Health J. 2004 10(6):778-88.A

20. Jeffery RW. Risk Behaviors and Health:Contrasting Individual and Population Perspectives. American Psychologist. September 1989;44( 9):1194-202. 